\title{
Current Status of Management on Pharmacopuncture in Korea through Introduction of an Accreditation System
}

\author{
Soo-Hyun Sung ${ }^{1}$, Byung-Cheul Shin², Min-Jung Park ${ }^{3}$, Kyeong Han Kim4, Ji-Won \\ Kim', Ji-Yeon Ryu' ${ }^{1}$, Jang-Kyung Park ${ }^{5 *}$ \\ 1 Department of Korean Medicine Policy, National Development Institute of Korean Medicine, Seoul 04554, South Korea \\ 2 Division of Clinical Medicine, School of Korean Medicine, Pusan National University, Yangsan 50612, South Korea \\ ${ }^{3}$ Department of Korean Medicine Policy, National Development Institute of Korean Medicine, Seoul 04554, South Korea \\ ${ }^{4}$ Department of Preventive Medicine, College of Korean Medicine, Woosuk University, Wanju, 55338, South Korea \\ ${ }^{5}$ Division of Clinical Medicine, School of Korean Medicine, Pusan National University, Yangsan 50612, South Korea
}

\section{Key Words}

pharmacopuncture, herbal acupuncture, external herbal dispensaries of traditional Korean medicine clinics, EHDs

\section{Abstract \\ Objectives: Pharmacopuncture is a new form of acu- puncture treatment that injects herbal medicine into acupuncture points. This paper introduces the manage- ment status of pharmacopuncture through accredita- tion, and examines the effect of accreditation on phar- macopuncture management.}

Methods: The Accreditation System of External Herbal Dispensaries (EHDs) of traditional Korean medicine clinics announced by the Ministry of Health and Welfare in September 2018 were investigated.

Results: The Accreditation System of EHDs assesses and certifies herbal medicine and pharmacopuncture preparations. Regular components for the 'pharmacopuncture' certification consist of nine standards, 30 categories, and 165 items. The nine standards include: herbal dispensary facilities, clean room management,

Received: May 28, 2019 Reviewed: May 31, 2019 Accepted: Jun 03, 2019

(1) This is an Open-Access article distributed under the terms of the Creative Common Attribution Non-Commercial License (http://creativecommons.org/licenses/by-nc/4.0/) which permits unrestricted noncommercial use, distribution, and reproduction in any medium, provided the original work is properly cited.

( This paper meets the requirements of KS X ISO 9706, ISO 9706-1994 and ANSI/NISO Z39.48-1992 (Permanence of Paper). management and organization operation, employee management, document management, continuous quality control, herbal medicine management, management of preparation, and pavement management.

Conclusion: Through EHD accreditation and certification system, traditional Korean medicine clinics and EHDs can now manage pharmacopuncture medicine quality and promise safe pharmacopuncture treatment for the people.

\section{Introduction}

Pharmacopuncture, also known as herbal acupuncture, is a new form of acupuncture treatment that injects herbal medicine into acupuncture points [1]. Acupuncture is based on the meridian theory, and herbal medicine is based on the Qi and flavor theories; therefore, pharmacopuncture is based on the traditional medicine theory [2, 3]. Pharmacopuncture has been applied to relieve pain associated with conditions such as rheumatoid arthritis, osteoarthritis, musculoskeletal diseases [4-6], and chronic pelvic pain [7]. Some studies have shown that pharmacopuncture has a significant influence on heart rate variability (HRV) [8-11], type 2 diabetes [12], and cancer [13].

In Korea, pharmacopuncture was first officially introduced to the traditional Korean medicine (TKM) community in 1967 by Sang-Cheon Nam [14]. While

"Corresponding Author

Jang-Kyung Park. Division of Clinical Medicine, School of Korean Medicine, Pusan National University, Yangsan 50612, South Korea.

Tel: +82-55-360-5978 Fax: +82-55-360-5978

E-mail: vivat314@pusan.ac.kr 
conventional acupuncture treatment incorporates the physical stimulation of associated meridians and acupoints, pharmacopuncture adds chemical ingredients from therapeutic herbs with pharmacological effects [2].

In Korea, pharmacopuncture treatment is one of the most commonly used methods in traditional Korean medicine clinics. Of the 123 traditional Korean medicine doctors who are part of the musculoskeletal specialist traditional Korean medicine center, 118 (95.9\%) have used pharmacopuncture for the treatment of lumbar disc herniation [15]. A survey of the frequency of pharmacopuncture usage in 4 years at 12 traditional Korean medicine institutions revealed that 32,947 (98.6\%) of 33,145 inpatients and 289,860 of 373,755 outpatients $(77.6 \%)$ received pharmacopuncture [16].

In general, medicinal products are managed by the ministry of food and drug administration (FDA). In Korea, pharmacopuncture is administered based on prescriptions issued by Traditional Korean medicine institutions and external herbal dispensaries (EHDs), facilities of Traditional Korean medicine institutions) to Traditional Korean medicine institutions [17]. Recently, the Korea Ministry of Health and Welfare (MOHW) has announced the introduction of EHDs evaluation accreditation and certification standards. In the certification standard system, two standards are presented: one for evaluating the EHDs of the traditional Korean medicine clinics that prepare pharmacopuncture, and another for evaluating the EHDs that prepare herbal medicine [18].

This paper introduces the management status of pharmacopuncture (traditional Korean medicine treatment) through accreditation, and examines the effect of accreditation on pharmacopuncture management. In addition, we hope this study will serve as a policy reference, and contribute to the institutionalization of traditional medicine.

\section{Concept of EHDs}

In 2008, the MOHW allowed the establishment of EHDs of medical institutions, and the joint usage of herbal dispensaries [17]. The established EHDs can be used jointly with Traditional Korean medicine institutions, and they play an important role in producing pills, powders, pastes, tablets, pharmacopuncture, etc., which are difficult to prepare in individual Traditional Korean medicine institutions. In December 2017, there were 98 standard EHDs, 15 herbal dispensaries preparing pharmacopuncture, 92 herbal dispensaries preparing herbal medicine, and nine herbal dispensaries preparing pharmacopuncture and herbal medicine [18].

The facility standard and management plan for the herbal dispensaries prepared in 2008 was the minimum standard for the herbal dispensaries of Traditional Korean medicine institutions. The same standard was applied to the EHDs [17]. However, there are aspects to which the current standard does not apply to, like the herbal dispensaries preparing larger and more varied formulations, particularly for pharmacopuncture. In this context, the MOHW introduced autonomous evaluation accreditation in 2018 to assert its own quality control rather than regulating through standard revision [18].

\section{Introduction of the Accreditation System of EHDs}

The Accreditation System of EHDs introduced in September 2018 assesses and certifies herbal medicine and pharmacopuncture preparations. The accreditation is applied separately to the EHDs preparing herbal medicine and those preparing pharmacopuncture. The EHDs that prepare herbal medicine are evaluated with 81 items reflecting the KGMP (Korean Good Manufacturing Practice for Injection) and Hazard analysis and critical control points (HACCP) standards, and those that prepare pharmacopuncture are evaluated with 165 items according to the KGMP standards. The accreditation system of the EHDs is autonomous, and a certification mark is granted if all the evaluation items are satisfied (Fig. 1). The standards of certification and the certification period are shown in Table 1.

\section{Evaluation Standards of P-EHDs}
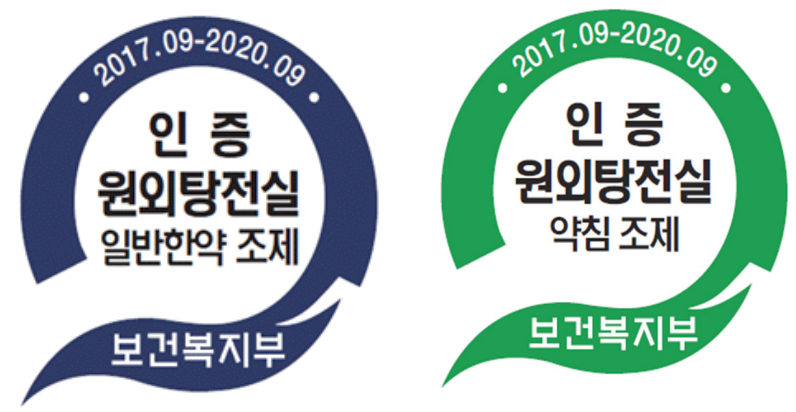

(a) Certification mark of EHDs preparing herbal medicine

(b) Certification mark of EHDs preparing pharmacopuncture

Figure 1 Certification mark of external herbal dispensaries (EHDs) of traditional Korean medicine clinics

Table 1 Criteria of accreditation class of external herbal dispensaries of traditional Korean medicine clinics preparing pharmacopuncture (P-EHDs)

\begin{tabular}{c|c|c}
\hline Acceditation class & Achievement standards(\%) & Duration of Accreditation \\
\hline Accreditation & $100 \%$ & 3 years \\
Non-accreditation & $<100 \%$ & Revaluation \\
\hline
\end{tabular}


Regular components for the 'pharmacopuncture' certification consist of nine standards, 30 categories, and 165 items. The nine standards include: herbal dispensary facilities, clean room management, management and organization operation, employee management, document management, continuous quality control, herbal medicine management, management of preparation, and pavement management (Table 2). Details of the certification standard can be found in the "External Herbal Dispensaries Certification Standard" published by the MOHW [18]. The main contents of the nine standards have been briefly summarized below.

\subsection{Herbal Dispensary Facilities}

The Herbal Dispensary Facilities standard assesses whether EHDs have the facility base to prepare safe pharmacopuncture. Forty-two evaluation items are divided into seven categories: facility management of herbal dispensaries, preparation support facilities, storage facilities, drainage facilities, lighting, anti-insect, and anti-heat.

\subsection{Clean Room Management}

The Clean Room Management standard also assesses whether the EHDs have the facilities to prepare safe pharmacopuncture. Twenty-four evaluation items are divided into four categories: classification of clean room and clean air equipment, monitoring of clean room and clean air device, management of clean room sanitation, and pharmacopuncture preparation environment.

\subsection{Management and Organization Opera- tion}

The Management and Organization Operation standard assesses whether external herbal dispensaries comply with legal workforce standards to provide safe pharmacopuncture. Eight items divided into three categories of organization, management, and operations are evaluated.

Table 2 Evaluation standard of external herbal dispensaries of traditional Korean medicine clinics preparing pharmacopuncture (P-EHDs)

\begin{tabular}{|c|c|c|}
\hline $\begin{array}{l}\text { Evaluation } \\
\text { Categories }\end{array}$ & Evaluation Parts & $\begin{array}{c}\text { Number of } \\
\text { Evaluation } \\
\text { Items }\end{array}$ \\
\hline \multirow{5}{*}{$\begin{array}{l}\text { 1.Herbal } \\
\text { Dispensaries } \\
\text { Facilities }\end{array}$} & 1.1 Facility Management & 25 \\
\hline & 1.2 Preparation Supporting Facilities & 9 \\
\hline & 1.3 Storage Facilities & 2 \\
\hline & 1.4 Drainage Facilities & 3 \\
\hline & 1.5 Prevention of Insect and Heat & 3 \\
\hline \multirow{4}{*}{$\begin{array}{l}\text { 2.Clean Room } \\
\text { Management }\end{array}$} & $\begin{array}{l}\text { 2.1 Classification of Clean Room and Air } \\
\text { Conditioning Equipment }\end{array}$ & 4 \\
\hline & $\begin{array}{l}\text { 2.2 Monitoring of Clean Room and Air } \\
\text { Conditioning Equipment }\end{array}$ & 6 \\
\hline & 2.3 Hygiene Management of Clean Room & 7 \\
\hline & $\begin{array}{l}\text { 2.4 Working Environment of Pharmacopuncture } \\
\text { Preparation }\end{array}$ & 7 \\
\hline
\end{tabular}




\begin{tabular}{|c|c|c|}
\hline $\begin{array}{l}\text { Evaluation } \\
\text { Categories }\end{array}$ & Evaluation Parts & $\begin{array}{c}\text { Number of } \\
\text { Evaluation } \\
\text { Items }\end{array}$ \\
\hline \multirow{3}{*}{$\begin{array}{l}\text { 3.Management and } \\
\text { Organization } \\
\text { Operation }\end{array}$} & 3.1 Organization & 3 \\
\hline & 3.2 Business Management & 4 \\
\hline & 3.3 Sessions Operation & 1 \\
\hline \multirow{3}{*}{$\begin{array}{l}\text { 4.Employee } \\
\text { Management }\end{array}$} & 4.1 Education & 3 \\
\hline & 4.2 Personal Hygiene Management & 12 \\
\hline & 4.3 Infection Control & 1 \\
\hline \multirow{2}{*}{$\begin{array}{l}\text { 5.Document } \\
\text { Management }\end{array}$} & 5.1 Production of Documents & 5 \\
\hline & 5.2 Archiving and Disposing of Documents & 2 \\
\hline \multirow{2}{*}{$\begin{array}{l}\text { 6.Continuous } \\
\text { Quality Control }\end{array}$} & 6.1 Quality Management System & 1 \\
\hline & 6.2 Complaints Management & 1 \\
\hline \multirow{2}{*}{$\begin{array}{l}\text { 7.Herbal Medicine } \\
\text { Management }\end{array}$} & 7.1 Herbal Medicine Management & 3 \\
\hline & 7.2 Storage, Use, and Disposal of Herbal Medicine & 8 \\
\hline \multirow{7}{*}{$\begin{array}{l}\text { 8.Management of } \\
\text { Preparation }\end{array}$} & 8.1 Process Management & 12 \\
\hline & 8.2 Sterilization Management & 10 \\
\hline & $\begin{array}{l}\text { 8.3 Filtration Work Management of } \\
\text { Pharmacopuncture Preparation }\end{array}$ & 5 \\
\hline & $\begin{array}{l}\text { 8.4 Final Work Management of } \\
\text { Pharmacopuncture Preparation }\end{array}$ & 7 \\
\hline & 8.5 Examination of Pharmacopuncture & 6 \\
\hline & 8.6 Preparation in Advance & 2 \\
\hline & 8.7 Checking the Preparation & 3 \\
\hline
\end{tabular}




\begin{tabular}{l|c|c}
\hline $\begin{array}{c}\text { Evaluation } \\
\text { Categories }\end{array}$ & Evaluation Parts & $\begin{array}{c}\text { Number of } \\
\text { Evaluation } \\
\text { Items }\end{array}$ \\
\hline $\begin{array}{l}\text { 9.Packaging } \\
\text { Management }\end{array}$ & 9.1 Management of Packaging Materials & $\mathbf{2}$ \\
\cline { 2 - 3 } & 9.2 Packaging Operation Management & $\mathbf{8}$ \\
\hline & TOTAL & $\mathbf{1 6 5}$ \\
\hline
\end{tabular}

\subsection{Employee Management}

The Employee Management standard assesses whether the EHDs provide opportunities for employee development, qualification maintenance, and professional development. The 16 evaluation items are divided into five categories: education, personal hygiene, shift work, employee complaints, grievance handling, contagion control, and infection control.

\subsection{Document Management}

The Document Management standard evaluates whether the EHDs are able to perform preparation tasks and hygiene management based on regulations, and whether procedures such as preparation, modification, and approval of various recorded documents are organized. Seven items in two categories of document production and document retention/disposal are evaluated.

\subsection{Continuous Quality Control}

The Continuous Quality Control standard assesses whether the management system for continuous quality improvement has been established, and the employees have been made aware of it and are evaluating it. Two items in two categories are evaluated: one for the quality management system for improving the quality of prepared pharmacopuncture, and another for handling the complaints and difficulties of the medical institutions.

\subsection{Herbal Medicine Management}

The Herbal Medicine Management standard evaluates the EHDs for thorough quality control of raw herbal medicines so that safe pharmacopuncture can be prepared. Eleven items in two categories of raw herbal medicine warehousing/inspection and raw herbal medicine storage/use/disposal are evaluated.

\subsection{Management of Preparation}

The Management of Preparation standard consists of eight evaluation categories and 45 evaluation items. First, in the water management section, water management regulations are established and obeyed to create suitable conditions for preparing safe pharmacopuncture. The four categories of process management, sterilization management, pharmacopuncture filtration, and final task management are composed of 12, 10, 5, and 7 evaluation items, respectively. These evaluate whether conditions for preparing safe pharmacopuncture are created by establishing and obeying the regulations related to preparation.

\subsection{Packaging Management}

Finally, in the packaging management standard, 10 items in two categories of packaging material management and packaging management are evaluated to assess whether pharmacopuncture is safely delivered in accordance with the packaging management principles in the EHDs.

\section{Discussion}

Pharmacopuncture is a new form of acutherapy that intends to cure diseases by injecting an extraction composed of one or many herbal medicines, into the meridian points $[2,3]$. Although this is similar to the injection method in terms of the mode of administration, pharmacopuncture is based on the theory of traditional Korean medicine, and is practiced by traditional Korean medicine doctors [19]. It differs from injection methods in that the traditional Korean medicine doctors prepare the medicine at the hospital or at a co-contracted EHD, based on the needs of the patient, thereby reflecting the specific characteristic of traditional Korean medicine, patient-oriented treatment.

There are two routes through which traditional Korean medicine institutions provide medicine to patients. First, the traditional Korean medicine doctor prescribes medicine manufactured by a pharmaceutical company authorized by the FDA. Second, the traditional Korean medicine doctor directly dispenses and combines the herbal medicine ingredients himself at traditional Korean medicine institutions or EHDs [20, 21]. Medicines provided through the second route are not covered by the national health 
insurance, which covers $39.0 \%-2.8 \%$ of the traditional Korean medicine clinic prescriptions and 54.7\%-64.7\% of the traditional Korean medicine hospital prescriptions $[22,23]$. In addition, on investigating the non-covered prescriptions given by traditional Korean medicine doctors, the rate of use of pharmacopuncture was found to be $67.5 \%$ and that of decoction of medical ingredients, $90 \%$ [23]. Since medicines used for pharmacopuncture vary according to the formulation and extraction method of the medical herbs, and are prescribed according to the characteristics and symptoms of the patients, the current provision method proves to be advantageous when compared to the conventional provision method, which manufactures and supplies uniform medicine.

Though injection is advantageous in that it can be administered to patients who have difficulty in taking the medicine orally, and can exhibit rapid effects because they do not go through gastrointestinal system, pharmacopuncture medicine requires stricter quality control, when compared to the other formulations [24]. Even if the FDA through the hGMP system approved the medical ingredients of the formulation, management and guidelines for storage and preparation of ingredients during the process of dispensing and hygiene and bacteriological management of facilities that guarantee aseptic medicine preparation are needed [25-27]. Therefore, it is important to strengthen supervision and control the preparation process.

In 2018, the MOHW introduced the concept of evaluation certification, and released the certification standard for EHDs, which originally operated autonomously [18]. The certification separates the evaluation of the EHDs that prepare pharmacopuncture medicine from those that prepare oral medicines, intending to strengthen the pharmacopuncture medicine by following the standards of KGMP injective medicine.

Originally, the medicines could only be prepared if the preparation room, herbal medicine storage facilities, water supply, drainage facilities, hygienic clothing preparation, and preparation logbook conditions were satisfied [17, 28]. However, as of now, in order to receive the evaluation certification, a quality assurance system that matches with the KGMP level of aseptic preparation in the aseptic drug manufacturing facility, installation of air conditioning, and clean zone management according to ISO international standards, along with validation items, preparation documents, and aseptic management are required [18].

The following items should be considered in the certification system for the continuous quality control of pharmacopuncture medicine.

First, verification of the validity of pharmacopuncture medicine is necessary. The current certification system includes the confirmation of aseptic test results of the medicine solution and the medicine preparation in a clean zone according to ISO international standards, as a certification standard for safety management [18]. However, the validity of each and every drug solution is not checked. Although not all procedures such as cell experiments, animal experiments, clinical trials, etc., that are required for FDA drug approval are necessary here, the certification evaluation should verify the minimum clinical evidence for patient treatment.
Second, standardization of the medicament containers is necessary. In case of products for FDA approval, appropriate dosage and container specifications for each medicine are verified at the item approval stage [29]. However, currently for pharmacopuncture, the medicine is contained in a variety of containers of different capacities (e.g., $2 \mathrm{ml}, 5$ $\mathrm{ml}, 10 \mathrm{ml}$, and $20 \mathrm{ml}$ ) based on the dispensary, lacking a set standard. The WHO guidelines recommend the use of single-dose vials to prevent contamination of the injectate [30]. In addition, the re-use of injection equipment including multi-dose vials and syringes could lead to the transmission of bloodborne viruses such as HIV, HBV, and HCV, as well as bacterial infections and abscesses at the injection site [32]. Therefore, it is necessary to reflect within the certification, the usage of a container that will guarantee only one-time usage for each individual medicine.

Third, the preparation procedure of pharmacopuncture medicine must be aseptic. The manufacture of sterile products is required to minimize the risks of microbiological, particulate, and pyrogen contamination worldwide [26]. Additionally, the FDA has been intimated to improve the safety and quality of sterile products [33]. Thus, in order to establish a safety verification system for the practice of pharmacopuncture, the medicines must be managed through a mandatory certification system.

The EHD accreditation and certification system embed a safety management system to the traditional preparation methods of pharmacopuncture medicine. The certification system has a great significance in bringing a systemized management to traditional medicine without infringing the traditional medicine preparation methods that incorporate the traditional Korean medicine treatment characteristic of patient-oriented treatment, and in establishing a safety management system.

\section{Conclusion}

In this time when pharmacopuncture medicine is being manufactured without specific standards, the EHD accreditation and certification system for medicine safety has been introduced. Through this system, traditional Korean medicine clinics and EHDs can now manage pharmacopuncture medicine quality and promise safe pharmacopuncture treatment for the people. It is our hope that in the future, the certification system will set in through voluntary and continuous involvement of herbal dispensaries, and will bring improvement of pharmacopuncture medicine quality control.

\section{Conflicts of interest}

The authors declare that there are no conflicts of interest regarding the publication of this paper.

\section{Acknowledgments}

This study was supported by a grant from the Project of National Development Institute of Korean Medicine, Accreditation of External Herbal Dispensaries of Traditional Korean Medicine Clinics, funded by the Korea Ministry of Health and Welfare. 


\section{References}

1. Park JM, Lee HS, Shin BS, et al. Pharmacopuncture in Korea: A systematic review and meta-analysis of randomized controlled trials. Evid Based Complement Alternat Med. 2016;2016:4683121.

2. Korean Pharmacopuncture Institute. Pharmacopuncturology. 2rd edition. Seoul: Elsevier Korea; 2012. 3-5.

3. Lim CS, Park SK, Sun SH, Lee KH. Research on Korean pharmacopuncture in south Korea since 2007. J Pharmacopuncture. 2014;17(4):15-21.

4. Chung JH, Kim YM, Bak JP, et al. The effect of pharmacopuncture with polygonum cuspidatum Sieb et Zucc. solution on collagen-induced arthritis in wistar rats. Korean J Acupunct. 2011;28(1):79-89 (Korean).

5. Shin SY, Seo DK, Kim SY, Seo JC, Seo YJ, Lee YJ, et al. The effect of Chinemys reevesii Gray pharmacopuncture for women with knee osteoarthritis acupuncture. J Acupunct Res. 2015; 32(3):163-73.

6. Lee OJ, Lee DG, Lee JH, et al. Effects of Curcuma longa LINNE pharmacopuncture at ST36 on adjuvant induced arthritis in rats. J Acupunct Res. 2013;30(4):95105.

7. Seong KM, Jang G, Kim DW, et al. Hwanglyunhaedok pharmacopuncture versus saline pharmacopuncture on chronic nonbacterial prostatitis/chronic pelvic pain syndrome. J Acupunct Meridian Stud. 2017;10(4):24551.

8. Kim HJ, Song BY, Yook TH. The effects of distilled Cervi Pantotrichum Cornu pharmacopuncture and Zizyphi Spinosi semen pharmacopuncture on the heart rate variability. J Pharmacopuncture. 2009;12:31-40.

9. Shin JC, Kim LH, Song BY, Yook TH. The effects of distilled Rehmannia glutinosa herbal acupuncture on the heart rate variability (HRV). J Pharmacopuncture. 2008;11:83-98.

10. Roh JD, Kim LH, Song BY, Yook TH. The effects of distilled wild Ginseng herbal acupuncture on the heart rate variability (HRV). J Pharmacopuncture. 2008;11:55-70.

11. Kim YJ, Lee CH, Kim JU, Yook TH. Effects of distilled Cervi Pantotrichum Cornu and Rehmannia glutinosa pharmacopuncture at GB21 (Jianjing) on heart rate variability: a randomized and double-blind clinical trial. J Acupunct Meridian Stud. 2016;9(6):311-8

12. Lee SW, Nam MH, Lee BC. Herbal acupuncture for type 2 diabetes: a meta-analysis. Exp Ther Med. 2017;13(6):3249-56.

13. Cheon S, Zhang X, Lee IS, et al. Pharmacopuncture for cancer care: a systematic review. Evid Based Complement Alternat Med. 2014;2014:804746.

14. Nam SC. Meridian. Seoul: Hang-Lim-Seo-Won Publications; 1967;4.

15. Shin YS, Shin JS, Lee JH, et al. A survey among Korea medicine doctors (KMDs) in Korea on patterns of integrative Korean medicine practice for lumbar intervertebral disc displacement: preliminary research for clinical practice guidelines. BMC Complement Altern Med. 2015;15(1):432.

16. Lee YJ, Shin JS, et al. Usage report of pharmacopuncture in musculoskeletal patients visting Korean medi- cine hospitals and clinical in Korea. BMC Complement Altern Med. 2016;16(1):292.

17. Korea Ministry of Health and Welfare. Guideline on Installation and Utilization of External Herbal Dispensaries of Traditional Korean Medicine Clinics and Share-use of Herbal Dispensaries From. http:// www.mohw.go.kr/react/jb/sjb0406vw.jsp?PAR_ MENU_ID $=03 \& M E N U$ ID $=030406 \& C O N T$ SE$\mathrm{Q}=342727$ \&page $=1$ (retrieved on 21 Nov 2018).

18. [Korea Ministry of Health and Welfare. Introduction of external herbal dispensaries of traditional Korean medicine clinics From. http://www. mohw.go.kr/react/al/sal0301vw.jsp?PAR_MENU_ ID $=04 \&$ MENU_ID $=0403 \&$ p a g $=1 \&$ CONT_SE $\mathrm{Q}=344877 \&$ SEARCHKEY $=$ TITLE\&SEARCHVAL$\mathrm{UE}=\% \mathrm{ED} \% 95 \% 9 \mathrm{C} \% \mathrm{EC} \% 95 \% \mathrm{BD}$ (retrieved on 21 Nov 2018).

19. Lee YJ, Shin JS, Lee J, et al. Usage report of pharmacopuncture in musculoskeletal patients visiting Korean medicine hospitals and clinics in Korea. BMC Complement Altern Med. 2016;16(1):292.

20. Choi DW, Kim JH, Cho WY, et al. Regulation and Quality Control of Herbal Drugs in Korea. Toxicology 2002;181182: 581-586.

21. Kim J, Kang DI. A descriptive statistical approach to the Korean pharmacopuncture therapy. J Acupunct Meridian Stud. 2010;3(3):141-9.

22. National Health Insurance Service. 2015 Survey on Medical Expenses of National Health Insurance Patients. Wonju: National Health Insurance Service; 2016.

23. Park JK, Kim KH. A survey on uncovered services in national health insurance of traditional Korean medicine institution. Korean J Prev Med. 2017;21(3):43-50.

24. Sufian MA, Uddin S, Islam T, et al. Quality control parameters based on pharmacopoeias. Indo Am. J. P. Sci. 2016;3(12):1624-38.

25. Ministry of Food and Drug Safety. Good manufacturing practice guideline for herb material. Osong: Ministry of Food and Drug Safety; 2013.

26. World Health Organization (WHO) (2011). WHO good manufacturing practices for sterile pharmaceutical products. Available: http://apps.who.int/medicinedocs/documents/s19959en/s19959en.pdf (retrieved on 02 Dec 2018).

27. Pharmaceutical Inspection Co-operation Scheme. Guide to good manufacturing practice for medicinal products annexes. PE 009-14. Geneva: Pharmaceutical Inspection Co-operation Scheme; 2018. 1-18.

28. Kim JH, Kim YK. A study on the facility standard of herbal dispensaries. J Korean Med. 2017;38(1):81-92.

29. Van Norman GA. Drug, devices, and the FDA: part 1: an overview of approval processes for drug. JACC Basic Transi Sci. 2016;1(3):170-9.

30. World Health Organization. WHO best practices for injections and related procedures toolkit. Geneva: World Health Organization; 2010.

31. Deshmukh MT, Salunkhe RS, Deshmukh VT, Shete RV. Quality control test's for parenteral preparations: a review. Journal of Current Pharma Research. 2015;5(2):1425-30.

32. World Health Organization. WHO guideline on the use 
of safety-engineered syringes for intramuscular, intradermal and subcutaneous injections in health care settings. Geneva: World Health Organization; 2016.

33. David H. Sterile products: advances and challenges in formulation, manufacturing and regulatory aspects-a regulatory review perspective. AAPS PharmSciTech. 2010;11(3):1482-4. 